\title{
Direct Production of Ti-Fe Alloy in Liquid by Electrowinning in Molten Slag
}

\author{
Toshihide TAKENAKA, ${ }^{1,2)}$ Hidetaka MATSUO ${ }^{2)}$ and Masahiro KAWAKAMI') \\ 1) Formerly Toyohashi University of Technology. Now at Kansai University, Yamate-cho 3-3-35, Suita, $564-8680$ Japan. \\ 2) Toyohashi University of Technology, Tempaku-cho, Toyohashi, 441-8580 Japan.
}

(Received on March 31, 2011; accepted on August 1, 2011)

\begin{abstract}
Aiming at the direct production of Ti-Fe alloy, its direct electrowinning has been attempted in a $\mathrm{CaF}_{2-}$ $\mathrm{CaO}-\mathrm{TiO}_{2}-\mathrm{FeO}$ bath by using a direct-current electro-slag remelting unit. The experiments were carried out in the slag where the molar ratio of $\mathrm{CaO}$ to $\mathrm{TiO}_{2}$ was fixed as 1.5, and the influence of the molar ratio of $\mathrm{FeO}$ to $\mathrm{TiO}_{2}$ was mainly investigated. The experimental results proved that Ti-Fe alloy in liquid could be obtained at the limiting bath compositional range. At the molar ratio of $\mathrm{FeO}$ to $\mathrm{TiO}_{2}$ was 0.90 , both the $\mathrm{Ti}$ content in the deposit and the cathodic current efficiency were the best under the conditions in this study; the Ti content reached about $50 \mathrm{wt} \%$, and the cathodic current efficiency also did about 50\% at best.
\end{abstract}

KEY WORDS: electro-slag remelting; Ti-Fe alloy; direct production; electrolysis.

\section{Introduction}

The addition of $\mathrm{Ti}$ in steel is effective in the elimination or inactivation of $\mathrm{C}, \mathrm{N}, \mathrm{S}$ and $\mathrm{O}$ because Ti has a strong affinity with these elements. Ferro-titanium (Ti-Fe alloy) is widely used for this purpose as well as Ti metal itself. Steel makers are one of the major users of Ti actually, and their Ti consumption must increase remarkably considering a great demand of high quality steel in future.

Titanium is not a rare element in the crust, and the natural resource of Ti is oxide ore because of its strong affinity with O. Conversely, this strong affinity limits the process of $\mathrm{Ti}$ metal production, and Kroll process is only the current industrial process. Kroll process which has been well developed gives Ti metal of very high quality, but includes inefficient steps. Therefore, the production cost of Ti metal is hardly lowered in the present situation, which obstructs the wider use of Ti metal. A breakthrough in Ti production has been strongly required to reduce the production cost. Actually, many well-designed processes have been proposed, ${ }^{1-3)}$ but they have not been industrialized yet.

Ferro-titanium is produced by remelting of iron/steel with Ti metal from Kroll process or Ti scrap. Ferro-titanium production from primary $\mathrm{Ti}$ metal is restricted by the issues of Kroll process, and that from $\mathrm{Ti}$ scrap has to depend on uncertain supply of Ti scrap. In the latter case, the contamination of alloying elements in Ti scrap must be also taken account of. The direct production of ferro-titanium from $\mathrm{Ti}$ natural resource is strongly required, though it has not been actualized.

Our group has been investigated the direct electrolysis of Ti by using a DC-ESR (direct current electro-slag remelting) unit. ${ }^{4)}$ In the process, a very high direct current passed through a slag bath containing $\mathrm{TiO}_{2}$, and Ti metal was electrodeposited on a cathode at the bottom of the container. In the case that the bath temperature was sufficiently high, Ti metal was deposited in liquid, and the cathodic current efficiency became rather high. Not only pure Ti metal, but also Ti-Al alloy could be directly obtained in a bath with $\mathrm{TiO}_{2}$ and $\mathrm{Al}_{2} \mathrm{O}_{3}$ by the same process. ${ }^{5)}$ It is reported that the cathodic current efficiency of the $\mathrm{Ti}-\mathrm{Al}$ electrolysis was better than that in the Ti electrolysis; it was inferred that the higher cathodic current efficiency was caused by the higher bath temperature due to the bigger consumed electric power with the change in the electric conductivity of the bath.

Electrolytic co-deposition of $\mathrm{Ti}$ with Fe is difficult normally in molten slag as well as in an aqueous solution considering the large difference between their redox potentials. ${ }^{6}$ However, there is a possibility of the co-deposition of Ti with $\mathrm{Fe}$ by the process using a DC-ESR unit because the very high cathodic reaction rate according to large direct current in the process may cause the insufficient supply of Fe ion to the cathode. Considering that major natural Ti resources are complexes of $\mathrm{Ti}$ and $\mathrm{Fe}$ oxides, the efficient process using Ti resources can be proposed. It is also regarded as the advantage of the proposed process that the process can be started and stopped easily, namely can be operated on demand.

In this study, direct electrodeposition of Ti-Fe alloy was attempted in a molten $\mathrm{CaF}_{2}-\mathrm{CaO}-\mathrm{TiO}_{2}-\mathrm{FeO}$ bath by using a small DC-ESR unit. From the analysis of the electrodeposit, the necessary conditions for effective Ti-Fe electrolysis were discussed. Since it had been shown that the composition of the slag bath had a remarkable influence on the Ti electrolysis ${ }^{7)}$ and $\mathrm{Ti}-\mathrm{Al}$ electrolysis, ${ }^{5)}$ the dependence on the bath composition was investigated in detail.

\section{Experimental}

Figure 1 illustrates the experimental setup. A watercooled $\mathrm{Cu}$ vessel $(110 \mathrm{~mm}$ in inner diameter, $400 \mathrm{~mm}$ in 


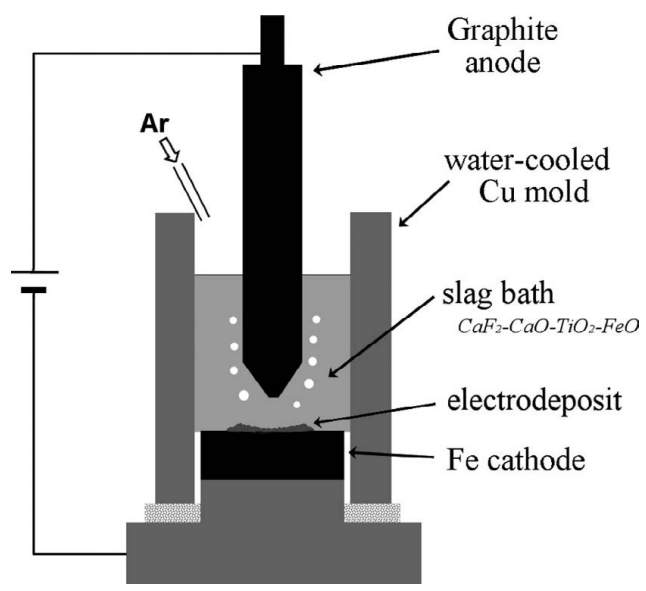

Fig. 1. Illustration of electrolysis cell.

height) was settled on a water-cooled $\mathrm{Cu}$ base-mold. The base-mold was connected to the minus terminal of a DC power supply (Sansha Electric MFG, current-controlled, maximum voltage: $100 \mathrm{~V}$, maximum current: $2 \mathrm{kA}$ ). A steel plate was set on the base-mold, and used as cathode. A graphite rod (50 $\mathrm{mm}$ in diameter) was suspended in the middle of the vessel, and acted as anode.

$\mathrm{A} \mathrm{CaF}_{2}-\mathrm{CaO}-\mathrm{TiO}_{2}-\mathrm{FeO}$ mixture was used as an electrolysis bath. A base slag was a commercial $\mathrm{CaF}_{2}-\mathrm{CaO}$ mixture (DENKA, 80:20 in weight) or a premelted $\mathrm{CaF}_{2}-\mathrm{TiO}_{2}$ mixture (made in our lab., 80:20 in mole), and the composition was adjusted by addition of $\mathrm{CaF}_{2}, \mathrm{CaO}, \mathrm{TiO}_{2}$ and $\mathrm{FeO}$ in it.

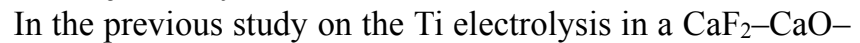
$\mathrm{TiO}_{2}$ bath, ${ }^{7)}$ it was shown that the cathodic current efficiency strongly depended on the molar ratio of $\mathrm{CaO}$ to $\mathrm{TiO}_{2}$ in the slag bath, $R_{\mathrm{CaO} / \mathrm{TiO} 2}$, and that the optimum ratio was 1.5 . Based on this result, the molar ratio of $\mathrm{CaO}$ to $\mathrm{TiO}_{2}$ was fixed as 1.5 in this study, while the molar ratio of $\mathrm{FeO}$ to $\mathrm{TiO}_{2}, R_{\mathrm{FeO} / \mathrm{TiO} 2}$, was varied.

The slag mixture was filled in the vessel, and electrolysis started by the so-called "cold-start" procedure. Electrolysis was carried out under a corrent-controlled condition with $\mathrm{Ar}$ blowing, and the distance between the graphite anode and the steel cathode plate was controlled to be about $30 \mathrm{~mm}$. Applied current was $1.2 \mathrm{kA}$ ordinarily, and the current and cell voltage were recorded during the operation. The cell voltage was altered with the conductivity of the bath, so that the consumed electric power changed consequently.

After the electrolysis, the electrodeposits and the solidified salt were taken out, and analyzed by EDX and XRD. The composition of the electrodeposit shown in this paper was an average at some points of the cross section of some deposits. The cathodic current efficiency was calculated from the weight of the deposit and the composition of electrodeposit with the presumption of the overall electrode reactions as follows;

$$
\begin{aligned}
& T i(\mathrm{IV})+4 e^{-}=T i \\
& F e(\mathrm{II})+2 e^{-}=F e
\end{aligned}
$$

\section{Results and Discussion}

Figure 2 shows a typical change in current and cell voltage during the electrolysis. In the beginning of electrolysis

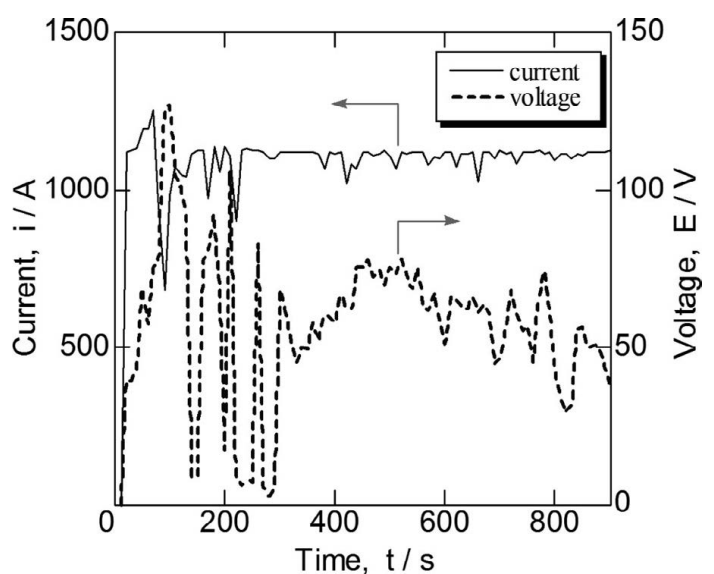

Fig. 2. Change in cell voltage and current during electrolysis $\left(\mathrm{i}_{\text {appl }}=\right.$ $\left.1200 \mathrm{~A}, R_{\mathrm{FeO} / \mathrm{TiO} 2}=0.90\right)$.
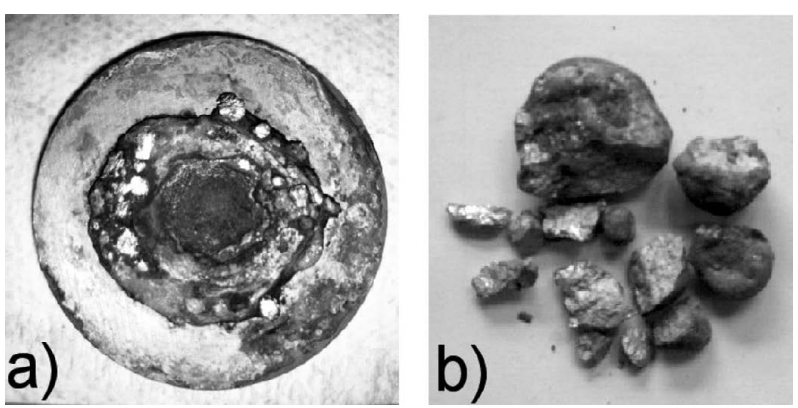

Fig. 3. Appearance of Fe cathode and metallic pieces after electrolysis. a) top view of cathode. b) metallic pieces from solidified salt.

by cold-start procedure, the slag mixture in solid was melted by arc discharge. Consequently, slag splashes were seen and the voltage oscillated violently. No electrodeposit was obtained under any electrolytic condition in the experiment where the electrolysis was stopped just after the voltage oscillation. After a few minutes, a molten slag bath was formed in the cell. The voltage oscillation calmed down though some slag splashes were still seen. Because a conduction current seemed to pass through the slag bath in this situation, the electrode reaction could be expected. Actually, the amount of the electrodeposit tended to increase with the electrolysis time after the subsidence of the voltage oscillation.

Metal deposit with smooth surface piled up on the cathode, and metallic pieces were also recovered from the solidified slag as shown in Fig. 3. The metallic pieces have a round and smooth surface. The appearance of the electrodeposits indicates that they deposited in liquid, same as the liquid deposits were obtained in the Ti-Al electrolysis by the same process. ${ }^{5)}$ The interface of the deposits on the cathode and the Fe base-plate was indistinct by melting, and the deposits could not be separated from the plate. The slag including water-insoluble $\mathrm{CaF}_{2}$ was also involved in the deposit. Therefore, the accurate composition of the whole deposit was hardly analyzed.

The amount of the electrodeposit depended on not only the electrolysis time mentioned above and also the composition of the slag bath. Figure 4 shows the dependence of the cathodic current efficiency on $R_{\mathrm{FeO} / \mathrm{TiO} 2}$. The cathodic 
current efficiency strongly depended on $R_{\mathrm{FeO} / \mathrm{TiO} 2}$, having a peak, about $50 \%$, at $R_{\mathrm{FeO} / \mathrm{TiO} 2}=0.90$ under the condition in this study. The cathodic current efficiencies in the Ti electrolysis in $\mathrm{a} \mathrm{CaF}_{2}-\mathrm{CaO}-\mathrm{TiO}_{2}$ bath and the $\mathrm{Ti}-\mathrm{Al}$ electrolysis in a $\mathrm{CaF}_{2}-\mathrm{CaO}-\mathrm{TiO}_{2}-\mathrm{Al}_{2} \mathrm{O}_{3}$ bath were reported to be strongly affected by the composition of the slag bath. The maximum efficiencies in the Ti electrolysis were about $25 \%$ at the molar ratio of $\mathrm{CaO}$ to $\mathrm{TiO}_{2}=1.5,{ }^{7)}$ while that in the Ti-Al electrolysis was about $50 \%$ at the molar ratio of $\mathrm{Al}_{2} \mathrm{O}_{3}$ to $\mathrm{TiO}_{2}=1.33$. $^{5}$ )

Figure 5 shows the relationship between $R_{\mathrm{FeO} / \mathrm{TiO} 2}$ and the consumed electric power. The consumed electric power was strongly influenced by $R_{\mathrm{FeO} / \mathrm{TiO} 2}$, because the electric conductivity changed with the composition and the operation was performed under a corrent-controlled condition with a similar distance between the electrodes. A similar dependence of the consumed electric power on the bath composition was also seen in the Ti electrolysis in $\mathrm{a} \mathrm{CaF}_{2}-\mathrm{CaO}-\mathrm{TiO}_{2}$ bath $^{7)}$ and the $\mathrm{Ti}-\mathrm{Al}$ electrolysis in a $\mathrm{CaF}_{2}-\mathrm{CaO}-\mathrm{TiO}_{2}-$ $\mathrm{Al}_{2} \mathrm{O}_{3}$ bath. ${ }^{5}$ In Fig. 5, the consumed electric power has a peak at $R_{\mathrm{FeO} / \mathrm{TiO} 2}=0.90$. The similarity is seen in the tendency in Fig. 5 and that in Fig. 4.

The influences of $R_{\mathrm{Fe} / \mathrm{TiO} 2}$ on the cathodic current efficiency shown in Fig. 4 and on the consumed electric power shown in Fig. 5 suggest the correlation between the consumed electric power and the cathodic current efficiency.

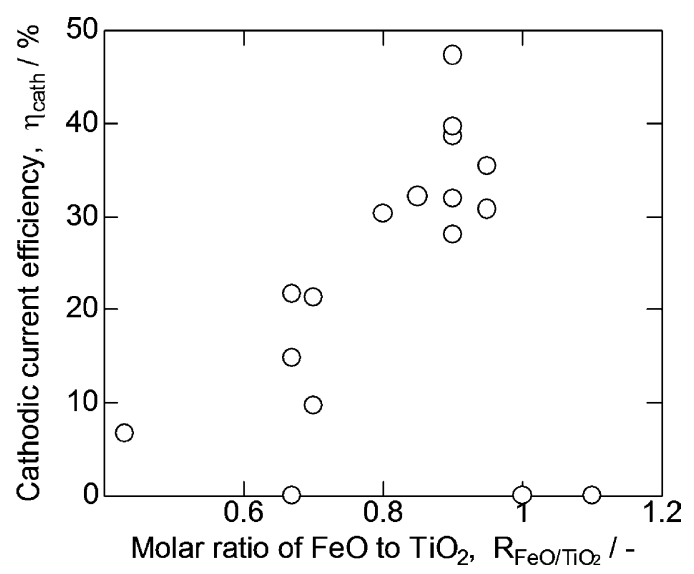

Fig. 4. Dependence of cathodic current efficiency on molar ratio of $\mathrm{FeO}$ to $\mathrm{TiO}_{2}$ in bath.

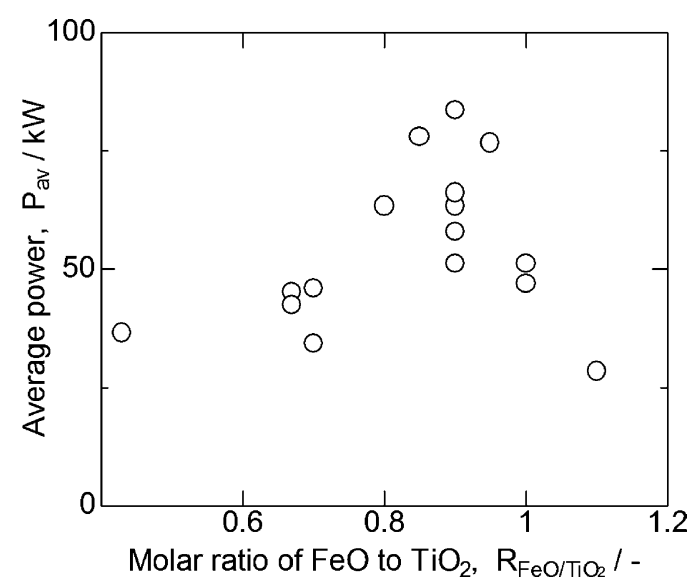

Fig. 5. Dependence of average consumed electric power on molar ratio of $\mathrm{FeO}$ to $\mathrm{TiO}_{2}$ in bath.
The relationship between the consumed electric power and the cathodic current efficiency in the Ti-Fe electrolysis is shown in Fig. 6, where those in the Ti electrolysis and the $\mathrm{Ti}-\mathrm{Al}$ electrolysis are also plotted. The cathodic current efficiency enlarged with the increase in the consumed electric power remarkably, and the results seem to be induced to the same relation regardless of the types of deposited metal. This relation can be explained by the indirect effect of the bath composition; the bath temperature was dominated by the consumed electric power, and the formation of a metalpool on the cathode at a high temperature was important to capture the deposit efficiently. This inference suggests that the dominant factor in the proposed process is not a high consumed power itself but a sufficient temperature. The operation with smaller energy can be expected by controlling the cooling of the system.

Figure 7 shows the Ti content in the deposit obtained in the various slag baths. The deposit usually consisted of Fe mainly, and the Ti content was very low. Only in the bath around $R_{\mathrm{FeO} / \mathrm{TiO} 2}=0.90$, the deposit containing $\mathrm{Ti}$ was obtained, and the Ti content shows a peak of $50 \mathrm{wt} \%$ at $R_{\mathrm{FeO} / \mathrm{TiO} 2}=0.90$. Figure 8 shows the typical XRD patterns of the deposits. Only the peaks of Fe were observed in the deposit obtained in the bath of $R_{\mathrm{FeO} / \mathrm{TiO} 2}=0.70$. Contrastively, a Ti-Fe compound was detected in the deposit from the bath

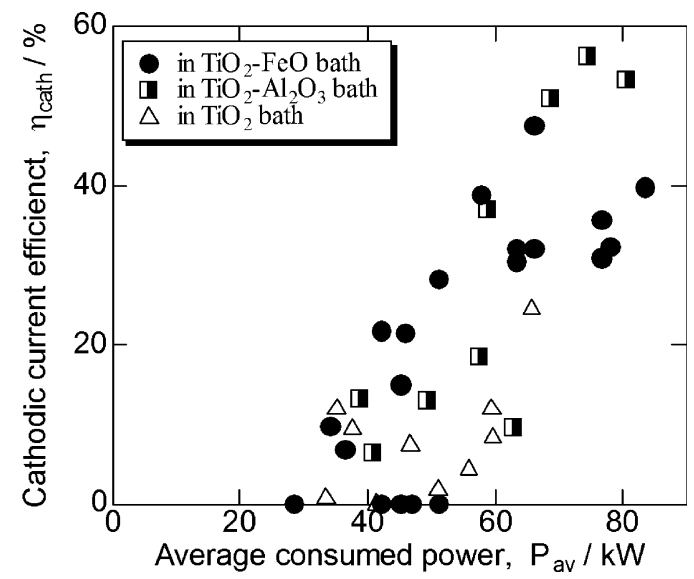

Fig. 6. Relationship between average consumed power and cathodic current efficiency with those in Ti electrolysis and $\mathrm{Ti}-\mathrm{Al}$ electrolysis.

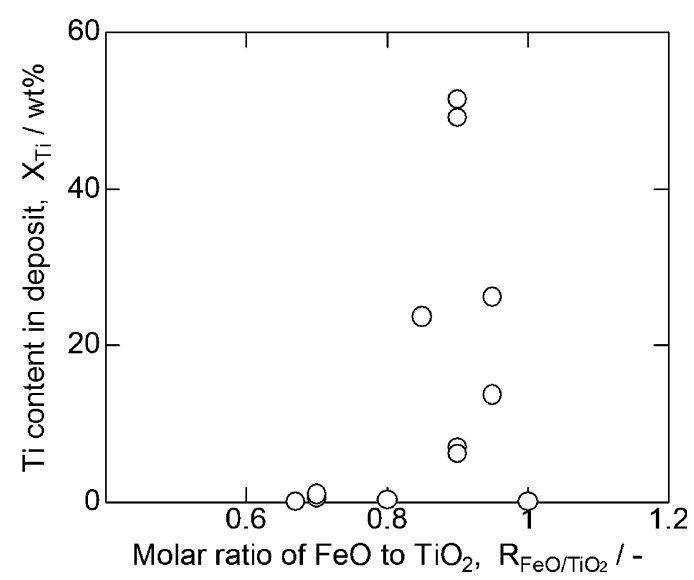

Fig. 7. Dependence of Ti content in deposit on molar ratio of FeO to $\mathrm{TiO}_{2}$ in bath. 


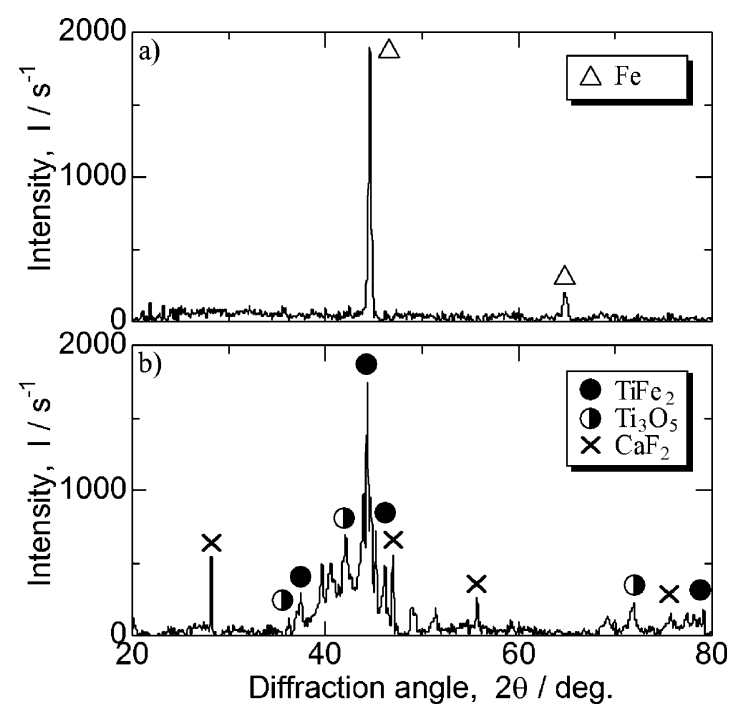

Fig. 8. XRD patterns of deposits $(\mathrm{Cu} \mathrm{K} \alpha)$. a) $\mathrm{i}_{\text {appl }}=1200 \mathrm{~A}, R_{\mathrm{FeO} / \mathrm{TiO} 2}=$ 0.70 . b) $\mathrm{i}_{\mathrm{appl}}=1200 \mathrm{~A}, R_{\mathrm{FeO} / \mathrm{TiO} 2}=0.90$.

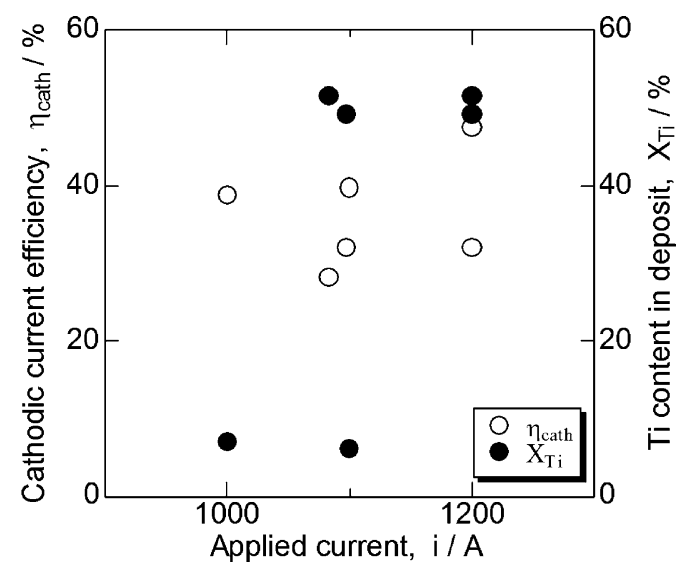

Fig. 9. Influence of applied current on cathodic current efficiency and $\mathrm{Ti}$ content in deposit $\left(R_{\mathrm{FeO} / \mathrm{TiO} 2}=0.90\right)$.

of $R_{\mathrm{FeO} / \mathrm{TiO} 2}=0.90$, though the diffraction peaks of lowvalent Ti oxide and unidentifiable peaks were found. These results are consistent with the results shown in Fig. 7.

The dependence of the cathodic current efficiency and the Ti content in the deposit on the applied current observed in the bath of $R_{\mathrm{FeO} / \mathrm{TiO} 2}=0.90$ was shown in Fig. 9. Both the current efficiency and the Ti content seemed to increase slightly with the increase with the current, but the correlations were unobvious. The applied current was considered not to be a dominant factor of the electrolysis under the condition in this study. However, because the applied current could not be changed so much to perform the electrolysis stably in this study, the further study on the influence of the applied current should be necessary.

The deposit containing Ti was obtained only in the bath around $R_{\mathrm{FeO} / \mathrm{TiO} 2}=0.90$ in the $\mathrm{Ti}-\mathrm{Fe}$ electrolysis, whereas $\mathrm{Ti}-\mathrm{Al}$ alloy was obtained in the bath of wider composition in the Ti-Al electrolysis. ${ }^{8)}$ Since the redox potentials of $\mathrm{Al}$ and $\mathrm{Ti}$ are close in various fused salt systems, ${ }^{6}$ the co-deposition of Ti with Al should not be difficult in the proposed process. Meanwhile, Ti is hardly reduced in various baths as compared with $\mathrm{Fe}^{6}{ }^{6}$ ) so the co-deposition cannot be explained from the view of equilibrium. From the result that the deposit containing Ti was obtained by the electrolysis with good cathodic current efficiency, it was suggested that the large cathodic overpotential and electrolysis current enabled the co-deposition of Ti with Fe kinetically. Even by the electrolysis in the bath of $R_{\mathrm{FeO} / \mathrm{TiO} 2}=0.90$, the Ti content fluctuated. Other conditions, such as the bath temperature and other balances of the bath composition except $R_{\mathrm{FeO} / \mathrm{TiO} 2}$, seemed to affect the electrolysis kinetically.

In the previous research on the Ti electrolysis in $\mathrm{a} \mathrm{CaF}_{2}-$ $\mathrm{CaO}-\mathrm{TiO}_{2}$ bath, ${ }^{7}$ it was inferred that the change in the bath composition caused the change in the Ti ion state in the bath and affected the electrode reaction consequently. In this study, the molar ratio of $\mathrm{CaO}$ to $\mathrm{TiO}_{2}$ in the electrolytic bath, $R_{\mathrm{CaO} / \mathrm{TiO} 2}$, was fixed as 1.5 based on this result. However, $\mathrm{CaO}$ should be an $\mathrm{O}$ donor, while $\mathrm{TiO}_{2}$ and $\mathrm{FeO}$ should act as acceptor. More efficient electrolysis of Ti-Fe by the process may be achieved by optimizing $R_{\mathrm{CaO} / \mathrm{TiO} 2}$ and $R_{\mathrm{FeO} / \mathrm{TiO} 2}$ in the bath simultaneously. To clarify the influence of the bath composition on the electrode reaction itself, the detailed electrochemical measurements is needed.

\section{Conclusion}

It was shown that $\mathrm{Ti}-\mathrm{Fe}$ alloy in liquid was directly obtained in a $\mathrm{CaF}_{2}-\mathrm{CaO}-\mathrm{TiO}_{2}-\mathrm{FeO}$ bath by the process using a DC-ESR unit, and the necessary condition was discussed.

The metal electrodeposit usually consisted of Fe, and the Ti content was very low. Only in the slag bath of the particular composition, the deposit contained Ti. The bath where the molar ratio of $\mathrm{FeO}$ to $\mathrm{TiO}_{2}, R_{\mathrm{FeO} / \mathrm{TiO}}$, was 0.90 was optimum from the Ti content in the deposit as well as from the cathodic current efficiency under the conditions in this study. The Ti content reached about $50 \mathrm{wt} \%$, and the cathodic current efficiency also did about $50 \%$ at best. These results are still insufficient for the actual production process, but the more efficient direct production of Ti-Fe alloy can be expected by further investigation to optimize the bath composition and the heat control more accurately.

\section{Acknowledgement}

This work was supported by ISIJ Research Promotion Grant (17th, 2008-2009).

\section{REFERENCES}

1) G. Z. Chen, D. J. Fray and T. W. Ferthing: Nature, 407 (2000), 344.

2) K. Ono and R. O.Suzuki: J. Miner., Met. Mater. Soc. (JOM), (2002), 59

3) M. Yamaguchi, Y. Ono, S. Kosemura, W. Kagohashi and T. Takenaka: Proc. 11th World Conf. Titanium (Ti-2007), The Japan Institute of Metals, Sendai, (2007), 143

4) T. Takenaka, T. Suzuki, M. Ishikawa and M. Kawakami: Electrochemistry, 67 (1999), 661.

5) A. Matsuyama, T. Kawabata, M. Sugawara, T. Takenaka and M. Kawakami: Proc. 11th World Conf. Titanium (Ti-2007), The Japan Institute of Metals, Sendai, (2007), 177.

6) A. J. Bard, ed., Encyclopedia of Electrochemistry of the Element, vol.X, Marcel Dekker, N.Y., (1976).

7) T. Takenaka, M. Sugawara, H. Matsuo, A. Matsuyama and M. Kawakami: ECS Trans., 16 (2009), 221.

8) T. Takenaka, H. Matsuo, M. Sugawara and M. Kawakami: Key Eng. Mater., 436 (2010), 85. 